\title{
Raça e antiescravismo no Caribe espanhol: 0 ativismo de Antonio Maceo e Ramón Emeterio Betances ${ }^{1}$
}

\author{
Race and Anti-Slavery in the Spanish Caribbean: the Political \\ Activism of Antonio Maceo and Ramón Emeterio Betances
}

Iacy Maia Mata*

\section{RESUMO}

É objetivo deste artigo discutir o antiescravismo no Caribe espanhol através da atuação do cubano Antonio Maceo (1845-1896) e do porto-riquenho Ramón Emeterio Betances (1827-1898). A pesquisa busca reconstituir o ambiente político do Caribe espanhol no período de 1863 a 1881, no contexto de guerras de independência, e o protagonismo específico de homens negros que reivindicaram solidariedade racial na luta pela abolição da escravidão. A partir de algumas correspondências e documentos produzidos por Maceo e Betances (ou com sua participação), e da documentação gerada pelas autoridades coloniais, serão discutidas a construção de redes e conexões transnacionais, com base racial, pelos ativistas que lutavam contra a escravidão e as discriminações e por direitos políticos integrais. Chamo especial atenção para a interlocução com os haitianos e para a insistente referência ao Haiti no vocabulário político daqueles ativistas.

Palavras-chave: Antiescravismo; raça; Caribe espanhol.

\section{Abstract}

This paper aims to discuss anti-slavery stances in the Spanish Caribbean through the actions of the Cuban Antonio Maceo (1845-1896) and the Puerto Rican Ramón Emeterio Betances (18271898). This research seeks to frame the political ambiance in the Spanish Caribbean from 1863 to 1881 , in the context of wars of independence, and the specific agency of black men who claimed racial solidarity in the struggle to abolish slavery. Drawing from correspondences and documents produced by Maceo and Betances (or with their participation), as well as documentation generated by colonial officials, I will discuss the building of race-based international networks and connections by the activists who fought against slavery, discrimination and for full political rights. I call special attention to the interlocution with the Haitians and the insistent reference to Haiti in their political vocabulary.

Keywords: Anti-slavery; race; Spanish Caribbean.

\footnotetext{
* Universidade Federal da Bahia (UFBA), Salvador, BA, Brasil. iacymaia@yahoo.com.br $<$ https://orcid. org/0000-0002-2790-9623>
} 


\section{DA “CUMPlicidAdE” ENTRE OS NEGROS DE DIFERENTES REgIÕES}

Em 1865, as autoridades coloniais espanholas temiam que eclodisse uma insurreição geral de negros no sul dos Estados Unidos, com ramificações no Caribe. Mesmo considerando que os receios eram exagerados e que a população branca do Sul estava armada e preparada para debelar qualquer movimento, o ministro da Espanha em Washington mostrara-se preocupado com as redes que se estavam estabelecendo entre negros de diferentes regiões. Segundo ele, "o estado de coisas era bastante crítico", e uma circunstância chamou ainda mais sua atenção sobre o assunto. A autoridade espanhola afirma ter tido notícia de que, naquele ano, ocorreram alguns conflitos provocados por negros na Virgínia e nas duas Carolinas, o que teria aumentado os temores da população branca do Sul americano. Mais ainda: soubera, através do Encarregado de Negócios da Espanha no Haiti, que "se apontava de antemão naquela ilha para o mesmo objetivo de uma insurreição geral” nos países escravistas, o que, para o cônsul, provava "não só o espírito hostil das populações negras, mas também a espécie de cumplicidade que se vai estendendo entre elas, cumplicidade criada e sustentada pela conspiração incessante das sociedades abolicionistas". ${ }^{2}$ Segundo o espanhol, a atividade das sociedades abolicionistas imbuía "o negro em espírito de propaganda antissocial", que tendia à "emancipação violenta e repentina nas regiões onde ainda exist[ia] escravidão”. ${ }^{3}$

Apesar do tom alarmista e de as revoltas não terem se confirmado, em alguma medida o representante da Espanha nos Estados Unidos tinha razão. Uma rede de cumplicidade e solidariedade transnacional entre negros estava sendo forjada na conturbada conjuntura de 1863 a $1881 .{ }^{4}$ Naquela ocasião, Cuba e Porto Rico, últimas possessões espanholas nas Américas, mergulharam em conspirações e insurreições com o fito de expulsar o que restava do império espanhol no Caribe. As duas colônias experimentaram a agricultura de plantation e a escravidão e estavam estruturadas em hierarquias raciais. Embora com diferente peso demográfico, a população negra era significativa nas duas regiões e teria participação decisiva nos acontecimentos políticos.

Os negros adultos das Antilhas daquele período testemunharam talvez o evento de maior importância para a sua geração: a abolição em um dos países mais comprometidos com a escravidão nas Américas. A Guerra Civil (18611865) dividiu os Estados Unidos e colocou a abolição na ordem do dia. Em $1^{\circ}$ de janeiro de 1863, a Proclamação da Emancipação na América do Norte retirou um forte argumento para a defesa da escravidão em Cuba (Knight, 1986, 
p. 56) e Porto Rico; a abolição, com o fim da Guerra Civil em 1865, libertou quatro milhões de cativos de uma só vez (Foner, 1988).

Naquele momento, o cubano Antonio Maceo morava com os pais e doze irmãos. O sítio em que vivia produzia café, tabaco, banana, entre outros produtos. Enquanto a família trabalhava na propriedade, Maceo e outro irmão eram encarregados de administrar a venda das colheitas no comércio de Santiago de Cuba (Franco, 1975, p. 201-203). No mercado provavelmente tivera notícia da guerra que se travava nos EUA e deve ter conversado com outros negros livres sobre o maior acontecimento daquela época. O jornal El Redactor, que circulava na cidade, publicava regularmente notícias sobre o conflito no Norte e há registros de que se cantava nos campos de Cuba "Avança, Lincoln, tu és nossa esperança” (Franco, 1975, p. 30; Scott, 1991, p. 51).

Quando eclodiu a Guerra Civil nos Estados Unidos, Maceo ainda não havia emergido na cena política do Caribe, mas outro caribenho já se tornara um importante ativista na luta contra a escravidão. Ramón Emeterio Betances, nascido em Porto Rico em 1827, ainda jovem, estudou medicina em Paris e atuou na Revolução de 1848, que aboliu a escravidão nas colônias francesas. Mas, antes de se estabelecer definitivamente em Paris, Betances, engajado na luta anticolonial, viajou para Santo Tomás, Haiti, República Dominicana, Venezuela e Nova York, seguido de perto por agentes e espiões a serviço da Espanha. Em 1858, em Porto Rico, fundou sociedades abolicionistas secretas - uma para libertar os recém-nascidos e outra para ajudar escravos fugidos a ir para outros lugares; essas ações o forçariam ao exílio (Suárez Díaz, 1980, p. 14-15). Em 1866, quando foi fundada a Sociedade Republicana de Cuba e Porto Rico em Nova Iorque, Betances estava presente (Buscaglia-Salgado, 2003, p. 246); a organização advogava a independência e a abolição da escravidão nas colônias espanholas (Reyes-Santos, 2013, p. 142).

Emeterio Betances esteve em Nova Iorque em curtas estadias logo após a Guerra Civil, em 1866 e 1869-70, quando estavam sendo dados os primeiros passos da Reconstrução no Sul (Suárez Díaz, 1980, p. 32). Durante a chamada Reconstrução Negra ou Reconstrução Radical, os ex-escravos tiveram acesso a direitos políticos integrais e exerceram uma "parcela efetiva do poder": o sufrágio negro permitiu o acesso a cargos públicos locais e era possível ver negros exercendo as funções de policial, xerife e prefeito (Foner, 1988, p. 74, 83, 93, 104, 119, 145; Scott, 2006, p. 27-48). Provavelmente, Betances teve, através da imprensa de Nova Iorque, contato com os escritos do abolicionista radical Wendell Phillips, que defendia a igualdade racial e a Reconstrução 
(Chaar-Pérez, 2013, p. 20-21). Posteriormente, traduziria um dos discursos de Phillips para o espanhol.

Parece que o contato com a utopia da Reconstrução deu ainda mais fôlego ao abolicionismo de Betances, pois, em 1867, após voltar ao Caribe para organizar comitês revolucionários, ele lançaria o documento Los Diez Mandamientos de los Hombres Libres, cujo principal artigo tratava da abolição da escravidão: "Considerando que de toda a história da humanidade, a escravidão tem sido, é e será a mais solene injustiça: Art. I - A escravidão fica abolida definitivamente e para sempre na Ilha de Porto Rico" (Suárez Díaz, 1980, p. 33). Apesar de lutar em várias frentes, no pensamento de Betances a abolição era prioridade absoluta (Suárez Díaz, 1980, p. 33). Em Nova Iorque, certamente Betances observou as barreiras raciais e a segregação formal que os negros enfrentavam, mas provavelmente levou para o Caribe sobretudo a mensagem de que a abolição e a experiência da Reconstrução inauguravam um período de utopias para a população negra.

Na esteira da Guerra Civil norte-americana, Cuba e Porto Rico logo viveriam suas próprias agitações políticas. Em 23 de setembro de 1868, a insurreição armada conhecida como Grito de Lares tentou, sem sucesso, a independência de Porto Rico. Betances trabalhou ativamente para a fracassada revolução, que pretendia não só a abolição da escravidão, como “o reconhecimento para o ex-escravo de todos os direitos do cidadão” (Espinal, 1983). Menos de um mês depois eclodiu, na região oriental de Cuba, a Primeira Guerra de Independência, que duraria dez anos (1868-1878). Um dos primeiros atos da guerra foi a proclamação da abolição formal da escravidão nas áreas dominadas pelos rebeldes. No conflito, os insurretos recrutaram escravos e formaram um Exército Libertador multirracial; muitos homens livres negros se envolveram na contenda no primeiro momento. Betances, ao ver o fracasso da investida anticolonial em sua terra natal, voltou-se para a guerra de Cuba, para a qual atuou ativamente, produzindo textos e discursos políticos, participando de reuniões e angariando fundos e armas para os rebeldes (Chaar-Pérez, 2013, p. 12).

Antonio Maceo ingressou nas forças rebeldes logo no início da insurreição (Franco, 1975, p. 41), quando tinha 23 anos, e foi, graças a seu enorme talento militar, ascendendo a posições de comando no interior do Exército Libertador. Em 1878, já na condição de General, Maceo protagonizou um dos episódios mais interessantes da história política de Cuba. Os espanhóis haviam acabado de selar com os insurretos o Pacto de Zanjón, que previa a saída da guerra (Scott, 1991, p. 128; Ferrer, 1999, p. 63). Por esse acordo, a paz foi 
selada sem a independência e sem a abolição. No conhecido Protesto de Baraguá, em reunião com o Comandante do Exército Espanhol Martínez Campos, Maceo insistiu que ele e seus homens só deporiam as armas se a Espanha garantisse a liberdade de todos os escravos de Cuba. Os espanhóis rejeitaram a proposta e Maceo afirmou que, apesar do Pacto de Zanjón, a guerra continuaria até que a Espanha concordasse com o fim da escravidão. Esse episódio conferiu a Maceo visibilidade e, daí em diante, seu nome tornou-se conhecido entre os observadores estrangeiros que acompanhavam o conflito, tornando-se "o tema que ocupou todas as mentes [...] o tema de todos os artigos da imprensa" (Zacaïr, 2005, p. 49).

A postura firme contra a escravidão frente aos espanhóis no Protesto de Baraguá, quando outros líderes cubanos pactuaram a saída da guerra sem a abolição, inscreveu o nome de Maceo no movimento abolicionista internacional; reconhecimento que foi, de pronto, registrado por algumas sociedades. Em abril de 1878, o Office of the American and Foreign Anti-Slavery Society ${ }^{5}$ enviou a seguinte mensagem para Maceo: "A escravidão é um crime contra a humanidade, e é dever das nações e indivíduos interferir pelos escravos onde quer que estejam". A mensagem foi assinada pelo Reverendo afro-americano Henry Highland Garnet, que, meses depois, convidou Maceo para uma reunião em Nova Iorque (Macías, 22 abr. 1878). Em outro documento, os abolicionistas da Sociedade Antiescravista de Nova Iorque fazem uma referência explícita ao Protesto de Baraguá:

Tenho enorme prazer na honra que me foi concedida de me dirigir a um ilustre Libertador como você. Minha Sociedade leu com infinito prazer suas honrosas e justas demandas em sua recente conferência com o General Martínez Campos. Você demandou a imediata abolição da escravidão como o Preço da sua lealdade. [...] Lembre-se dos apelos de meio milhão de seus semelhantes escravizados, cuja única oportunidade nesta vida de provar os frutos da liberdade depende de sua ação (Scottron, 17 abr. 1878).

Maceo, a partir daquele momento, entrou definitivamente para a cena pública internacional e para a história política do Caribe espanhol. Segundo Ada Ferrer, para Maceo, a luta pela abolição da escravidão em Cuba era tão importante quanto a luta pela independência (Ferrer, 1999, p. 84). Em uma carta a Máximo Gómez, Maceo afirmava que a sua missão era mais nobre e mais digna de consideração porque não era melhor "lutar em um partido político para dominar mais que trabalhar pelo bem de uma coletividade que sofre 
os horrores da escravidão". Maceo afirmava que lutava pela independência para com ela obter "a regeneração de um povo humilhado pela servidão" (Maceo, 18 y 23 jun. 1886; Maceo, 6 fev. 1880).

Na correspondência pessoal de Maceo, a causa da abolição da escravidão tornar-se-ia a justificativa para a luta anticolonial. Em uma carta em que pedia auxílio para a "sua empresa da liberdade", justificou o pedido pelos "motivos de caridade e de justiça a meus semelhantes", e "para que o resto da humanidade que ainda sofre a crueldade espanhola [...] se livre do peso que a oprime e possa entrar no caminho dos livres". O destinatário, segundo Maceo, sabia "melhor que ninguém a situação dos cubanos e muito particularmente dos escravos. Estes continua[va]m sofrendo a degradação dos seus cruéis verdugos" (Maceo, maço 95, documento 49, s.d.).

A empresa da liberdade a que se referia Maceo era uma nova insurreição, começada em 26 de agosto de 1879, que ficou conhecida como Guerra Pequena, deflagrada por líderes negros e brancos descontentes com a saída da Guerra de Dez Anos. Naquele novo conflito (1879-1880), muitos negros ganharam projeção política e Maceo tornou-se uma das principais lideranças (Scott, 1991, p. 107-108; Ferrer, 1999, p. 70-92). Maceo foi acusado de estar à frente do movimento, dando a este "o caráter de guerra de raça com objetivo de chamar a si a boa e honrada população de cor” (Polavieja, 10 dez. 1880, p. 6).

A narrativa da insurreição anticolonial, no entanto, fundava-se na aliança inter-racial. A criação de um exército multirracial, a abolição nominal da escravidão e o recrutamento de escravos uniam, sob a manta do nacionalismo cubano, negros e brancos contra os espanhóis. ${ }^{6}$ Maceo, mesmo sob constante acusação e suspeição de estar fomentando a guerra racial, foi um dos artífices dessa aliança inter-racial. Em vários momentos, negou pretender "ter intenções de sobrepor os homens de cor aos homens brancos" (Pichardo Viñals, 1973, p. 394-397). Em escrito público, agradeceu a colaboração e o empenho de ingleses, que tanto honravam a Rainha Victoria "com suas liberdades", para que "os homens das raças negra e branca que sofrem em Cuba os horrores da tirania" livrassem da "escravidão os trezentos mil negros que jazem submetidos à mais cruel opressão” (Maceo, maço 95, documento 51, s.d.).

Em um chamamento aos cubanos negros para que se incorporassem à Guerra Pequena, Maceo pedia que eles se unissem aos "brancos, filhos do país, que defendem vossos direitos, e sereis felizes". Convocava-os a expulsar de Cuba os espanhóis, "inimigos da humanidade do negro", cujo governo "os explora, para tiranizar mais e mais vossa raça”. Só sob um governo cubano estariam abertas para os negros as sendas do saber e dos direitos sociais (Maceo, 1998, p. 
112). Mais tarde, em 1882, Maceo receberia uma carta de José Martí recriminando tanto os que "promovessem em Cuba ódios" (ou se aproveitassem dos que existiam) quanto aqueles que pretendessem "sufocar as aspirações legítimas à vida de uma raça boa e prudente que já havia sido bastante desgraçada”. Para o independentista branco, o problema cubano residia não apenas na questão política, mas na social, cuja solução não se podia "lograr senão com aquele amor e perdão mútuos de uma e outra raça” (Martí, 2016, p. 236).

\section{APELO À SOLIDARIEDADE RACIAL}

No espaço público e na interlocução com os insurretos e abolicionistas brancos raramente Maceo enfatizou o seu pertencimento à "raça de cor". ${ }^{7}$ No entanto, em alguns momentos de sua trajetória expressou uma aguda consciência das discriminações raciais e se insurgiu contra elas. Em 1876, quando já era Brigadeiro do Exército Libertador, escreveu uma carta ao Presidente da República em Armas, Tomás Estrada Palma, defendendo-se da acusação de querer sobrepor os "homens de cor" aos brancos. Segundo Maceo, um grupo havia manifestado não querer servir sob suas ordens por ele ser "de cor". Sua resposta foi taxativa: pertencia à classe de cor, "sem que por isto se considere valer menos que os outros homens". Além disso, Maceo reivindicou fazer "parte não desprezível desta República democrática, que estabeleceu como base principal a Liberdade e a Fraternidade, e que não reconhece hierarquias" (Pichardo Viñals, 1973, p. 394-397).

Outro episódio em que Maceo manifestou seu pertencimento racial ocorreu em 1879, em meio à Guerra Pequena, quando o Governador Geral Ramón Blanco reeditou um decreto proibindo a entrada na ilha de "gente de cor" procedente de qualquer porto estrangeiro (Franco, 1975, p. 194). O objetivo era impedir que negros emigrados que viviam em outras ilhas do Caribe retornassem para Cuba e fortalecessem a nova insurreição. Para responder a esta medida, os emigrados em Kingston, Jamaica, redigiram um documento intitulado Los negros y mulatos cubanos residentes em Jamaica, ante la America Independiente:

Tamanha disposição é o ultimato de guerra que se faz à raça a que pertencemos, que ele nos obriga a interromper as hostilidades e a chamar para nossas fileiras os homens de cor de todas as partes para denunciar este ato frente ao mundo civilizado. [...] porque os homens que descendemos da raça africana em Cuba não temos nada que buscar à sombra da bandeira de Castela, a não ser as correntes da 
servidão e o desprezo pelas cores da nossa pele. [...] Somos de Cuba e estamos e estaremos com todos os que se agrupem à sombra de sua bandeira. Mas não estamos nem estaremos, nem são nossos irmãos, os que, ainda que nascidos em seu solo desafortunado, peçam o ostracismo de nossa raça e não mirem como seu o ensinamento tremulado às margens do Yara (Los negros... 26 out. 1879, fl. 511).

Tentando tecer redes transnacionais de solidariedade racial, os signatários do manifesto dirigiam-se à "América Independente" e exortavam "os homens de cor de todas as partes" a denunciar aquele feito diante do "mundo civilizado". No manifesto, emerge um protesto contra as hierarquias e as barreiras raciais enfrentadas pelos "livres de cor": estavam "excluídos da vida regular das sociedades civilizadas"; não podiam aspirar a cargos públicos; a sociedade, a religião e até a maçonaria erigiam para eles, em Cuba, "muros inacessíveis", graças ao domínio colonial. Reivindicavam direitos políticos para todos os que, em função da cor, estavam à margem, "fora da lei”, sendo apenas "máquinas de trabalho" (Los negros... 26 out. 1879, fl. 511).

Maceo vivia exilado na Jamaica no mesmo período e provavelmente foi um dos redatores da carta (Maceo, maço 95, documento 95, s.d.). Mas o general escolheu dar também uma resposta pessoal e afirmou que a resolução era um ataque explícito à "dignidade da raça de cor, à qual tenho a honra de pertencer"; e, como não podia assistir indiferente a "uma declaração de guerra à minha raça", dirigia-se, através da imprensa, aos povos civilizados do mundo, em especial "aos interessados", referindo-se possivelmente aos negros cubanos e estrangeiros. Para o insurreto, a bandeira de independência de Cuba abrigava todos os homens, "de qualquer origem ou raça"; "ali se luta pela igualdade do homem e pela emancipação da escravidão” (Maceo, 1998, p. 111-112). Ainda na Jamaica, Maceo escreveu o proclama "Viva Cuba Independente", em que, em um dos trechos, dirigiu-se diretamente aos escravos para dizer-lhes que era a maldade do opressor que os mantinha no cativeiro, pois "o homem negro é tão livre quanto o branco" (Maceo, 1998, p. 106).

Com a missão de fortalecer a insurreição e libertar os escravos, Maceo estreitou laços com líderes políticos, abolicionistas, insurretos e independentistas de todo o Caribe através de uma intensa troca de correspondências. Embora não emitisse discursos públicos acerca de necessidade de organização com base em linhas raciais, quando tratava com interlocutores negros do Caribe, Maceo reivindicava solidariedade, mobilizando o sentimento de pertença racial. Em carta endereçada ao presidente interino do Haiti, Maceo escreveu: 
[em Cuba] a maior parte da população, composta de homens da nossa raça, se vê privada de todos os direitos políticos e civis e sujeita às mais estúpidas preocupações e ali, enfim, 350 mil homens jazem ainda na mais dura servidão e nascem e morrem sob o férreo jugo da escravidão. [...]

Eu não sou, General, o embaixador de um governo que quer propor a outro uma aliança mais ou menos proveitosa; sou o emissário de um povo escravo que luta para conseguir sua independência a outro povo de sua mesma origem, que goza já de vida própria e que, demasiado guerreiro, não deixará de estender a seus irmãos uma mão protetora. Ao Senhor me dirijo, general, [...] conheço faz tempo a elevação de seus sentimentos humanitários e o seu amor à liberdade, sei que o Senhor tem sido sempre um dos mais valentes defensores de nossa raça e que, em épocas anteriores, o Senhor já prestou eminentes serviços à causa da liberdade em Cuba (Maceo, 23 set. 1879).

Embora tenha sido um dos grandes arquitetos da vitoriosa aliança inter-racial lograda nas lutas pela independência de Cuba, Maceo parecia acreditar que os negros deveriam desempenhar um papel específico na luta contra a escravidão. Na mesma carta ao general Joseph Lamothe, que lhe prestava auxílio para a organização de uma nova expedição a Cuba (Franco, 1975, p. 190191), Maceo escreveu que os escravos eram "demasiado frágeis para romper os grilhões da escravidão" sozinhos e, ao verem os "homens de cor" que tiveram "a fortuna de não nascer na escravidão ou de haver nos libertado dela, nos pedem nosso auxílio. Nosso dever é concedê-lo; negá-lo seria um crime" (Maceo, 23 set. 1879; Duharte Jimenez, 1984, p. 68). Para Maceo a libertação dos escravos era tarefa dos negros.

A experiência do porto-riquenho Ramón Emeterio Betances é bem diferente da de Maceo, mas talvez o seu antiescravismo também fosse inspirado pela mesma motivação. A Espanha aboliu a escravidão em Porto Rico em 1873. Isso, no entanto, não arrefeceu o compromisso de Betances com a agenda antiescravista. Em 18 de maio de 1879, em Paris, Victor Hugo presidiu, em um banquete no restaurante Bonvalet, uma cerimônia em comemoração ao $31^{\circ}$ aniversário da abolição da escravidão nas colônias francesas. Entre os presentes estava o Doutor Betances, e o ato foi dedicado aos "nossos compatriotas das colônias" e "aos escravos de Cuba” (Suárez Díaz, 1980, p. 45-46). Para José Luciano Franco, Ramón E. Betances personificou o sentimento progressista e democrático dos países do Caribe (Franco, 1975, p. 81). 
Figura 1 - Antonio Maceo

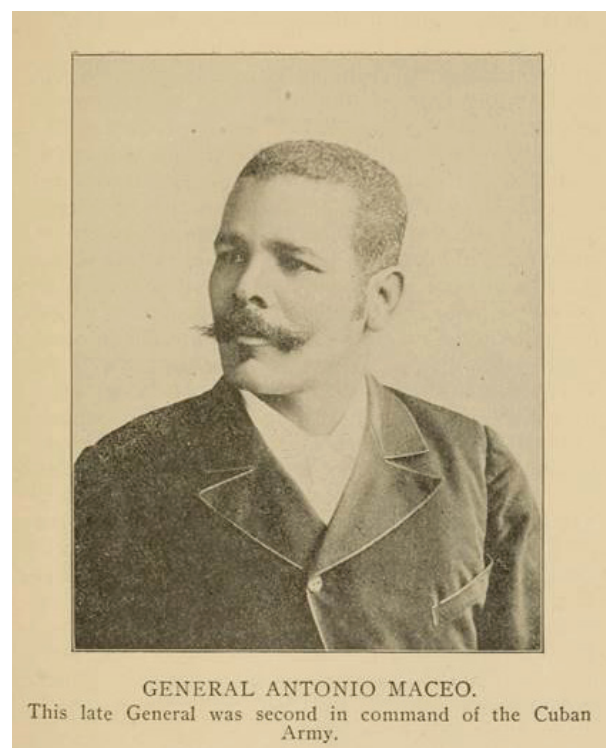

Fonte: Washington, Williams,

Wood, 1900, apud Peake, 2018.

Como afirma Josianna Arroyo-Martínez, a maior parte dos historiadores que se debruçam sobre a trajetória e o pensamento de Betances insiste em entendê-lo a partir das narrativas nacionais de democracia racial. Poucos lançam luz sobre suas "conexões diaspóricas e transnacionais". Betances, para a autora, representa o “imaginário negro’ da nação caribenha” (Arroyo-Martínez, 2011). O mesmo pode ser dito para Maceo. O ativismo destes homens ia além da luta por soberania nacional e incorporava uma agenda transnacional contra a escravidão. O meu argumento é de que esse compromisso político dos homens negros livres com a abolição foi moldado pela sua condição racial, que foi percebida por eles como parte da luta antirracista em nível transnacional. A luta pela abolição foi o primeiro elo a ligar homens negros, de diferentes tons de pele, condição social, origem e nacionalidade em um ativismo político que extrapolava a ideia de Estado-nação.

Chaar-Pérez argumenta que "a identidade racial, negra ou mestiça, nunca teve um papel privilegiado na visão revolucionária desenvolvida por Betances", que, no escrito político intitulado "A Cuba Livre: Ensaio sobre Alexandre Petión” não faz qualquer referência à raça (Chaar-Pérez, 2013, p. 23). Esse texto traça uma linha de continuidade entre a Revolução de São Domingos, a 
formação do Haiti independente e a guerra de independência de Cuba, buscando estabelecer as proximidades entre as duas insurreições. Para o autor, Betances representou o herói haitiano Alexandre Petión desracializado, sagrado, como síntese das virtudes do republicanismo francês, personificando o espírito vivo da Revolução Francesa no Caribe. A afirmação de que "há colonos conservadores como existem agora negros conservadores" demonstraria a desconfiança de Betances em relação aos discursos que conferiam valor político à identidade racial (Chaar-Pérez, 2013, p. 23-24, 43-44). No entanto, o próprio Betances, em outras ocasiões, parecia validar o pertencimento racial como leitmotiv para o ativismo político antiescravista. Em um discurso contra a escravidão proferido em uma loja maçônica em Porto Príncipe, dirigindo-se a um público haitiano, Betances afirmou que a Europa e a França não eram as únicas responsáveis por apoiar a causa da abolição:

Qual é o povo, mais que qualquer outro, que tem o direito de tomar a defesa destes oprimidos? Seus corações já disseram: é Haiti, são os senhores mesmos. Os senhores são maçons, são haitianos; os senhores são os homens da igualdade, são os filhos daqueles grandes cidadãos, que primeiro souberam conquistar para sua raça os direitos civis e políticos (Betances; Ojeda Reyes; Estrade, 2008, p. 116). ${ }^{8}$

Figura 2 - Ramón Emeterio Betances

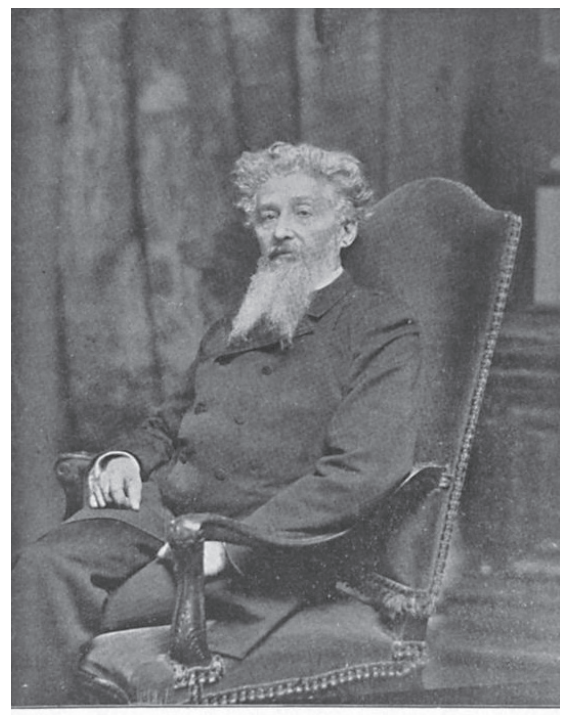

El Honorable Dr. Betances,

Fonte: El Honorable Dr. Betances. 
Um dado que ainda precisa ser mais explorado na biografia de Emeterio Betances é que ele era considerado na época "mulato" e se orgulhava disso. Como Maceo, publicamente Betances não costumava fazer qualquer referência à sua condição racial; assinava os textos identificando-se como porto-riquenho, caribenho ou, mais comumente, "O Antilhano". A sua assinatura como antilhano seria um indício de que Betances nunca reivindicara pertencimento racial e apostara na construção de uma subjetividade regional; isso também atestaria a filiação do porto-riquenho ao republicanismo francês e a sua identificação como latino (Chaar-Pérez, 2013, p. 15-16), não como de cor.

Mais do que o cubano Maceo, Betances fazia parte de uma intrincada rede de aliados em vários países que incluía brancos, criollos (descendentes de espanhóis nascidos na América hispânica), franceses, norte-americanos - abolicionistas e/ou anticolonialistas -, o que não significa que não tivesse uma aguda percepção da sua condição racial. Originalmente, as certidões de batismo de Betances e de suas irmãs foram registradas no livro de pardos, mas, para que sua irmã mais velha se casasse com um catalão, o pai deles solicitou um atestado de pureza de sangue e o conseguiu; no ano de 1840, a certidão foi registrada no livro de brancos com a seguinte observação: "trasladada ao presente livro de brancos por disposição do Superior General em 13 de maio de 1840" (Suárez Díaz, 1980, p. 1; Arroyo-Martínez, 2011). A decisão, comunicada a Betances em 1848, não foi bem recebida. Em carta à irmã, queixava-se de que haviam retirado o sangue africano da família:

por estar em consonância com a lei espanhola, havia de ser feita informação de brancura [...] e de provar-se, aos olhos de todos, que nós, gente preta, éramos tão brancos quanto qualquer Pelayo e até como qualquer irlandês, se era necessário, o que ficou provado ao fim, segundo a lei, que põe meia noite às doze do dia (Suárez Díaz, 1980, p. 7).

Anos depois, em uma carta à irmã, Betances, apesar de "legalmente" branco, escreveu: "somos prietuzcos, e não negamos isso" (Suárez Díaz, 1980, p. 9; Buscaglia-Salgado, 2003, p. 319). Se a abolição era um tema central no ativismo de Betances, o fim das discriminações raciais não ficava atrás: a Sociedade Republicana de Cuba e Nova Iorque, da qual foi fundador, tinha como bandeiras a independência das Antilhas espanholas e a liberdade absoluta de seus habitantes "sem distinção de raça ou cor" (Knight, 1986, p. 151; Cepero Bonilla, 1971, p. 102-103).

A identificação de Betances com as Antilhas não exclui a percepção e o 
reconhecimento da sua condição racial, já que, para ele, os antilhanos eram, na sua maioria, "gente de cor". Enquanto os criollos autonomistas reivindicavam a hispanidade e representavam Porto Rico como a legítima filha da Espanha, para Betances a ilha era "demograficamente constituída pela 'raça de cor" (Reyes-Santos, 2013, p. 144). Além dessa referência direta à população negra, o vocabulário político de Betances fez diversas alusões não explícitas à raça. Ao referir-se ao futuro dos libertos no pós-abolição sob o domínio espanhol, afirmou: "nada improvável que, sob outro nome, reapareça a escravidão, como para os chineses livres de Cuba, esse Regulamento de Trabalho, a Ku Klux Klan da liberdade" (Reyes-Santos, 2013, p. 144). Não por acaso, já na década de 1880, em Paris, Betances tornar-se-ia amigo e aliado do haitiano Anténor Firmin, autor do livro De la igualdad de las razas humanas (1885), que faz uma crítica contundente ao racismo "científico" (Chaar-Pérez, 2013, p. 12). Raça era um tema inescapável para aqueles ativistas.

\section{AliançAS RACIAIS}

Uma das inspirações para a formulação da reivindicação de direitos políticos integrais para os negros no Caribe hispânico foi, sem dúvida, o Haiti. A experiência da Revolução de São Domingos atraiu, desde muito cedo, a atenção da população negra - livres e escravos - e tornou-se parte do vocabulário político contra a escravidão. No início do século XIX, circulavam artefatos do Haiti e imagens de Toussaint L' Ouverture e Dessalines entre a "gente de cor" de Havana; escravos envolvidos em conspirações na primeira metade do século XIX fizeram referência direta à Revolução de São Domingos (Ferrer, 2004, p. 179-231; Childs, 2011, p. 252-263). Uma conspiração escrava em Porto Rico ocorrida em 1812 teve como influência decisiva a coroação de Henri Christophe no Haiti (Pinto, 2012, p. 121-149).

O próprio Antonio Maceo leu biografias de Toussaint L'Ouverture (Ferrer, 1999, p. 58) e Emeterio Betances traduziu “Toussaint L'Ouverture - Discurso de Wendell Philips", que foi distribuído gratuitamente entre cubanos e porto-riquenhos residentes em Nova Iorque (Suárez Díaz, 1980, p. 35; Arpini, 2008, p. 138-141). Em diferentes momentos, durante a década de 1870, Betances e Maceo estiveram no Haiti: ali participaram de reuniões, discursaram em lojas maçônicas, reuniram-se com líderes políticos, estreitaram laços com membros do Partido Liberal e solicitaram apoio para a independência de Cuba e Porto Rico. ${ }^{10}$

Philipe Zacaïr, no brilhante artigo "Haiti on His Mind: Antonio Maceo 
and Caribbeaness", ressalta a singularidade (e a proximidade) de Betances e Maceo na defesa da inclusão do Haiti na Confederação ${ }^{11}$ caribenha; os dois ativistas partilhavam a noção de que cubanos, porto-riquenhos, dominicanos e haitianos formavam um só povo (Zacaïr, 2005, p. 61). O autor, no entanto, não está interessado em analisar como a categoria raça foi mobilizada no discurso de Maceo. Apesar de constatar que Maceo apelou para a solidariedade racial ao solicitar ajuda do presidente haitiano Lysius Felicité Salomon, argumenta que a luta de Maceo estava estritamente "associada ao ideal de Caribbeaness" (Zacaïr, 2005, p. 64, 71, 72).

Maceo percebia nitidamente os obstáculos que enfrentava no jogo político interno ao campo anticolonial devido à sua condição racial; Betances, também ciente da sua origem mestiça, reconhecia o peso demográfico dos negros em Porto Rico. Longe de um ativismo desracializado, aqueles homens exibiam uma prática política informada por suas identidades raciais. ${ }^{12} \mathrm{O}$ que não quer dizer que estavam encerrados/encapsulados em suas afinidades raciais. Transitavam, constituíam redes com brancos de diferentes origens nacionais, reconheciam a necessidade das alianças políticas inter-raciais. Mas, em sua militância antiescravista, raça tornou-se uma categoria fundamental. No caso de Maceo, especificamente, há uma eleição de "aliados políticos naturais" contra a escravidão (Reyes-Santos, 2013, p. 143). Ao justificar o pedido de ajuda aos haitianos para a guerra de independência, Maceo afirmou que buscou "proteção no povo haitiano e no presidente Salomón em favor dos homens de sua raça que em Cuba sofrem os horrores do sistema colonial", por considerar-se "o mais indicado que qualquer outro para obter [a proteção] deles por eu pertencer à sua mesma raça”" (Maceo, 6 fev. 1880).

A liderança política do movimento independentista de Cuba e Porto Rico era majoritariamente branca e muitos desses líderes tentavam afastar o destino de Cuba da experiência do Haiti, considerado por muitos como "antítese da civilização” (Zacaïr, 2005, p. 47-48, 72). Mesmo os partidários da confederação caribenha, que advogavam a necessidade da unidade política das grandes Antilhas e exibiam uma "consciência caribenha" e um "nacionalismo pan-caribenho”, como o cubano José Martí e o porto-riquenho Eugenio María de Hostos, reportavam-se em geral à República Dominicana, a Cuba e a Porto Rico e silenciavam sobre o Haiti (Zacaïr, 2005, p. 50; Gaztambide Géigel, 2008, p. 48). Ambos brancos, nunca viram o Haiti como modelo e excluíram o país negro de seu projeto de confederação do Caribe (Chaar-Pérez, 2013, p. 14, 19; Arroyo-Martínez, 2011). Betances e Maceo, no entanto, afastavam-se dos próceres brancos ao evocar a experiência do Haiti. ${ }^{13} \mathrm{E}$, ao fazê-lo, incorporavam 
no vocabulário político antiescravista e anticolonial a identidade racial. Como afirma Rebecca Scott, qualquer referência ao Haiti era, por si só, uma "velada referência à raça” (Scott, 2006, p. 230). Se o Haiti representava, na imaginação colonial (e anticolonial) branca, o medo, para os ativistas negros tornou-se uma "ideologia de emancipação" (Arroyo-Martínez, 2011).

$\mathrm{Na}$ correspondência de Maceo, encontramos um projeto de estreitamento de laços políticos entre Cuba e a nação negra:

Falando em nome de Cuba, me atrevo a assegurar ao Haiti o mais profundo agradecimento pelos serviços [...] na obra da sua independência [...]. Sr. General, não necessito ressaltar a seus olhos as vantagens que resultariam de uma aliança entre ambos os países que, povoados por uma mesma raça, teriam que sustentar os mesmos princípios e defender os mesmos interesses (Maceo, 23 set. 1879).

Betances, ao imaginar uma confederação do Caribe, incluiu o Haiti (Chaar-Pérez, 2013, p. 11-36). Mais do que isso, a Revolução de São Domingos, símbolo das lutas antiescravista e anticolonial e, por isso mesmo, "um dos piores pesadelos da imaginação colonial”, tornou-se uma experiência fundamental no ativismo e no vocabulário político de Betances contra a Espanha (Reyes-Santos, 2013, p. 145). Em 1882, publicou uma carta em um volume intitulado "Os detratores da raça negra e a República do Haiti"; e em um debate com um jornalista francês, Betances rebateu a "alegada covardia da raça negra”, reafirmando o discurso de Wendell Philips de 1869 sobre a vitória de Toussaint contra os três principais exércitos europeus (Espanha, França e Inglaterra) (Reyes-Santos, 2013, p. 145-146).

Como Maceo, também Betances acreditava na necessidade das alianças inter-raciais para eliminar a escravidão e derrotar o poderio espanhol. O texto de Phillips traduzido por Betances ressalta a clemência de L'Ouverture para com os brancos e silencia sobre Dessalines - dessa forma a temida revolução negra poderia dialogar com o público abolicionista branco e referendar o apelo à solidariedade inter-racial (Chaar-Pérez, 2013, p. 19). No panfleto "A Cuba Livre”, em defesa da guerra anticolonial de Cuba, Betances exalta as ligações entre Alexandre Pétion (Presidente da República do Haiti) ${ }^{14}$ e Simón Bolívar, reivindicando-os como precursores da gesta revolucionária, ao mesmo tempo em que dá especial destaque ao papel desempenhado pelo haitiano nas guerras de independência no continente. Pétion enviou tropas para auxiliar Bolívar, também solicitando que a escravidão fosse abolida nos territórios independen- 
tes. Reyes-Santos argumenta que, mais uma vez, a ênfase recai sobre a unidade inter-racial (Reyes-Santos, 2013, p. 146-148).

Como Maceo, Betances defendia a aliança entre negros e brancos contra a Espanha. Ao se dirigir aos haitianos em uma reunião de maçons, o porto-riquenho valorizou a experiência do Exército Libertador, “onde todas as raças disputavam a honra de segurar em Cuba, contra a Espanha, a mesma bandeira que vocês fizeram triunfar contra o poder da França” (Betances, 2013, p. 116). Mas, em "A Cuba Livre", Betances faz questão de mencionar que um dos feitos de Alexandre Pétion foi organizar "um partido composto de todos os homens de sua raça sem distinção de matizes” (Betances, 2013, p. 220). E continua: Pétion e Toussaint expulsaram de sua terra "a raça que, por tantos anos violando nela o sagrado do lar e da consciência, ultrajando os direitos mais santos à honra e à vida, havia profanado a cada instante e durante séculos, todas as leis da humana dignidade" (Betances, 2013, p. 221-222). Por sua vez, Philips anuncia que faria a biografia "de um negro puro cujo sangue nunca se mesclou com o dos brancos" e sustenta o argumento de que "a raça negra, em vez de ser um objeto de compaixão e desprezo, como cremos geralmente, tem direito, julgando-a pelos feitos que apresenta a história, a ocupar um posto imediato à saxã" (Betances, 2013, p. 179-180). Para Betances, não havia "apologia mais eloquente" em favor da raça que o discurso de Wendell Phillips, que oferecia à reflexão "a vida de um negro que foi um dos maiores homens dos tempos modernos” (Betances, 2013, p. 296). A unidade inter-racial não excluía, na imaginação anticolonial e antiescravista daqueles ativistas negros, a identidade racial. Ao posicionar-se contra a escravidão, assumiam a defesa da raça (Betances, 2013, p. 294-295). A supremacia de uma raça sobre a outra deveria dar lugar à igualdade entre as raças, só conquistada com a "assimilação pela justiça, em lugar da unidade pelo extermínio” (Betances, 2013, p. 290).

Ao lançar luz sobre o papel histórico desempenhado por Touissaint e Petión nas lutas antiescravistas e anticoloniais, o porto-riquenho ressalta e valoriza o protagonismo de homens negros nas grandes transformações sociais. A tradução de Betances do discurso de Wendel Phillips sobre Toussaint foi publicada no La Revolución, o jornal oficial do comitê revolucionário de Cuba e Porto Rico, sediado em Nova Iorque; o texto "A Cuba Livre" foi escrito no Haiti, mas também publicado em Nova Iorque em 1871 (Chaar-Pérez, 2013, p. 16). Ali residia uma comunidade de emigrados cubanos e porto-riquenhos ligados à luta anticolonial.

Chaar-Pérez afirma que é impossível assegurar quem realmente lia $\mathrm{La}$ Revolución, mas podemos imaginar para quem Betances escrevia, a quem diri- 
gia seus textos. Seus escritos eram direcionados a uma gama diversa de leitores: ativistas, intelectuais e políticos criollos e europeus envolvidos diretamente ou simpatizantes da luta anticolonial. ${ }^{15}$ Mas, pelo local de publicação dos principais escritos que tematizavam o Haiti, um dos públicos-alvos eram os imigrantes de Cuba e Porto Rico nos EUA, que inclusive contribuíam financeiramente para a insurreição anticolonial. E entre esses trabalhadores havia uma significativa população negra. ${ }^{16}$ Fazer referência ao Haiti no momento em que havia uma guerra em Cuba era arriscado (Zacaïr, 2005, p. 54), e São Domingos, para muitos brancos, representava o "perigo negro" (Scott, 2006, p. 230). Exaltar a experiência e os heróis haitianos para trabalhadores negros continha uma mensagem clara: os homens negros "têm a coragem assim como as habilidades intelectuais para liderar um movimento político e militar” (Reyes-Santos, 2013, p. 146). Esses ativistas correram o risco de reivindicar a Revolução de São Domingos em meio à guerra contra a Espanha para "afirmar a humanidade dos afrodescendentes no Caribe” (Reyes-Santos, 2013, p. 145) ${ }^{17}$ em uma época de hegemonia das teorias raciais. Teciam laços de solidariedade racial transnacionais e construíam uma narrativa histórica que ultrapassava os limites do Estado-nação. Imaginavam uma sociedade em que homens negros ocupassem o lugar de próceres e heróis da luta contra a escravidão e enunciavam, no discurso político, o seu pertencimento racial.

Estes ativistas negros construíram redes de solidariedade transnacional em torno da luta contra a escravidão e, em alguma medida, se distanciaram dos independentistas criollos, ao apresentar um vocabulário político que evocava raça e buscava aproximação política com o Haiti. Reivindicavam para si, além de identidades nacionais específicas (cubano, porto-riquenho), geográficas e culturais (antilhano, americano, latino), o pertencimento à raça de cor, talvez o que explica o seu inabalável compromisso com a abolição da escravidão e com o fim das discriminações raciais. Esses homens desafiaram os projetos de identidade nacional dos seus aliados brancos na empreitada anticolonial ao exibir seu pertencimento racial e reivindicar, como parte de sua própria história, a revolta escrava e a libertação do Haiti.

\section{CONSIDERAÇÕES FINAIS}

Betances morreu em 1898, na França, e Maceo, em 1896, na terceira guerra de independência de Cuba. Ainda em vida, tornaram-se referências para a população negra de diferentes nações. ${ }^{18}$ Em uma reunião do Clube Político Duas Antilhas, em Nova Iorque, já em meio à terceira guerra de independên- 
cia de Cuba (1895-1898), o general colombiano Haníbal de Castro, voluntário no exército libertador de Cuba, fez um caloroso discurso. Naquele momento, já abolida a escravidão em todas as Américas, as alianças inter-raciais no interior do movimento independentista cubano estavam mais sedimentadas e o discurso nacionalista, mais coeso e centrado na cidadania inclusiva e na fraternidade racial, evitava tocar no tema raça (Ferrer, 1999). No entanto, o colombiano insistia na mesma pauta:

Para desprestigiar esta Revolução Cubana neste país [...] se apelou ao sentimento da raça de cor e nós na Venezuela e Colômbia tivemos o negro, o negro é a raça privilegiada, a triunfou [sic] em Carobobo e Ayacucho; e um negro no meu país é a figura mais proeminente: o Dr. Betances; a raça negra, a raça generosa, a viril, a valente teve seu berço no Egito, pátria do negro e mãe da civilização e do progresso [...]. Na linha de Reis Espanhóis houve sangue negro (Bravo) e hoje um negro é o primeiro Cubano (Bravo) Maceo, Viva Maceo! [...]. Conheci na Colômbia o S. Maceo e vários jovens que lhe acompanhavam [...] desde ali ofereci meus serviços a Cuba [...] com muito prazer [sigo] a cumprir a palavra que ofereci a Maceo (Castro, 1895, p. 47-50).

Não consegui identificar a condição racial do orador colombiano, mas é significativo que, em seu discurso, tenha pleiteado a extensão do uso do pronome Don para os negros. Em Cuba, esse era um designativo usado para pessoas brancas (Paquette, 1988, p. 43). Na plateia, seguramente, estavam muitos homens negros dos mais atuantes na luta anticolonial. O clube, formado com o objetivo de fortalecer a guerra contra a Espanha entre os emigrados, elegeu como seus presidentes honorários Maceo e Betances e demonstrou, pela sua atuação, que alguns líderes porto-riquenhos viram raça como um aspecto crucial na luta anticolonial (Hoffnung-Garskof, 2001, p. 14). Um dos ativistas negros pertencentes ao clube fez um tributo a Maceo como "o homem que reivindica sua raça" (Hoffnung-Garskof, 2001, p. 19).

Naquele mesmo ano, um texto circulou em Nova Iorque, anônimo, com ideias anarquistas. O autor desconhecido escreveu o panfleto "Cuba Libre. Mision Providencial. Ideas de Maceo, jefe de la raza negra em Cuba”, e fez uma interpretação do Protesto de Baraguá. Segundo o escrito, naquele episódio, Martínez Campos, representante da "orgulhosa Espanha", teve que "pedir a paz ao chefe da raça negra, a Maceo", que estava investido por sua raça para uma missão providencial, e lutava na terceira guerra de Cuba não para libertá-la da tirania dos espanhóis; sua missão era maior que apenas ajudar os bran- 
cos: ele era o "salvador dos negros, o Washington de sua raça" (Cuba Libre, 1895). Outro panfleto que circulou na Filadélfia, desta feita escrito por um pastor que exaltava os feitos militares de Maceo, demonstra como o cubano tornou-se, ainda no século XIX, um símbolo transnacional para os negros (Troy, 1900).

$\mathrm{Na}$ década de 1890, Maceo seria elogiado por suas proezas militares no jornal fundado por ativistas afro-americanos de Nova Orleans. ${ }^{19}$ No contexto da Redenção e na luta dos afro-americanos para a manutenção dos direitos conquistados com a Reconstrução Radical, o simbolismo de Antonio Maceo foi mobilizado quando ativistas afro-americanos de Nova Orleans solicitaram a incorporação nas companhias de voluntários que iam, sob a bandeira norte-americana, lutar na Guerra de Independência de Cuba (1895-1898). Em um poema dedicado aos voluntários negros, o nome de Maceo aparece ao lado de Toussaint L'Ouverture:

Vós, filhos de uma raça guerreira

Revivais o prestígio de vossos pais

E com vosso valor ganheis o assento

Em que a glória arde com radiante claridade

Junto a esses grandes heróis, bravos e puros

Homens como Maceo e Toussaint L'Ouverture ${ }^{20}$

Maceo e Betances são representantes de um grupo mais amplo de homens negros que se envolveram nas principais disputas políticas do seu tempo. Assim como os líderes haitianos antes deles, seus nomes foram incorporados ao vocabulário político de outros contemporâneos e das gerações seguintes que protagonizaram a luta política mobilizando a identidade racial. A atuação destes caribenhos na segunda metade do século XIX constitui, portanto, um capítulo importante da luta transnacional contra as discriminações raciais.

\section{REFERÊNCIAS}

ARPINI, Adriana María. Abolición, independencia y confederación: Los escritos de Ramón Emeterio Betances, "El Antillano". Cuyo. Anuario de Filosofía Argentina y Americana, v. 25, p. 119-144, 2008.

ARROYO-MARTÍNEZ, Jossianna. Revolution in the Caribbean: Betances, Haiti and the Antillean Confederation. 2011. Disponível em: http://www.habanaelegante.com/ Spring_Summer_2011/Invitation_Arroyo.html. Acesso em: 02 set. 2019. 
BETANCES, Ramón Emeterio; OJEDA REYES, Félix; ESTRADE, Paul (Editores). Obras completas. Vol. IV. San Juan: Ediciones Puerto, 2013.

BETANCES, Ramón Emeterio; OJEDA REYES, Félix; ESTRADE, Paul (Editores). Escritos políticos: Proclamas, discursos, estudios. Ramón Emeterio Betances. Obras completas. Volumen IV. San Juan de Puerto Rico: Ediciones Puerto, 2008.

BLACKBURN, Robin. A queda do escravismo colonial: 1776-1848. Rio de Janeiro: Record, 2002.

BUSCAGLIA-SALGADO, José F. Undoing Empire: Race and Nation in the Mulatto Caribbean. Minneapolis: University of Minnesota Press, 2003.

CASTRO, Haníbal de. Atas do Club Político Las Dos Antillas; p. 47-50 (Schomburg Center). 06 out. 1895.

CEPERO BONILLA, Raúl. Azúcar y abolición. La Habana: Editorial de Ciencias Sociales; Instituto Cubano del Libro, 1971.

CHAAR-PÉREZ, Kahlil. “A Revolution of Love”: Ramón Emeterio Betances, Anténor Firmin, and Affective Communities in the Caribbean. The Global South, Blomington: Indiana University Press, v. 7, n. 2, p. 11-36, 2013.

CHILDS, Matt D.; PÉREZ-CONCEPCIÓN, Hebert. La rebelión de Aponte de 1812 en Cuba y la lucha contra la esclavitud atlántica. Santiago de Cuba: Editorial Oriente, 2011.

CUBA LIBRE. Cuba Libre: Misión Providencial; El programa de Maceo. Nova Iorque, 1895.

DUHARTE JIMENEZ, Rafael. Dos aproximaciones a la historia de Cuba. Santiago de Cuba: Casa del Caribe; Imprenta de la Dirección Provincial de Cultura de Santiago de Cuba, 1984.

ESPINAL, Fulgencio. En torno a la Independencia y el Antillanismo. Conferencia ditada por el licenciado Fulgencio Espinal, el 27-2-83 en San Juan. Edición a cargo del doctor Ismael Hernández Flores. Santo Domingo, República Dominicana: Loteria Nacional, 1983.

EXPEDIENTE INSTRUIDO... Expediente instruido sobre temores de una insurrección de negros en el Sur de los Estados Unidos. Assuntos Políticos. Do Ministro de S.M.I. em Washington Al Excmo. Sr. Gobernador Capitan General de la Isla de Cuba, Washington (Arquivo Nacional de Cuba, ANC). 29 dez. 1865.

FERRER, Ada. Cuba en la sombra de Haití. Noticias, sociedad y esclavitud. In: GONZÁLES-RIPOLL, María Dolores; NARANJO OROVIO, Consuelo; FERRER, Ada; GARCÍA RODRIGUEZ, Gloria; OPATRNÝ, Josef (Orgs). El rumor de Haití en Cuba. Temor, Raza y Rebeldía, 1789-1844. Madri: Consejo Superior de Investigaciones Científicas, 2004. p. 179-231.

FERRER, Ada. Insurgent Cuba. Race, Nation, and Revolution, 1868-1898. Chapel Hill: The University of North Carolina Press, 1999. 
FONER, Eric. Nada além da liberdade. A emancipação e seu legado. Rio de Janeiro: Paz e Terra, 1988.

FRANCO, José Luciano. Antonio Maceo: apuntes para una historia de su vida. 3. Ed. Rev. La Habana: Editorial de Ciencias Sociais, 1975.

GAZTAMBIDE GÉIGEL, Antonio. La geopolítica del antillanismo en el Caribe del siglo XIX. Memorias. Revista Digital de Historia y Arqueología desde el Caribe, Barranquilla, Colombia: Universidad del Norte, Año 4, n. 8, p. 41-74, 2008.

HELG, Aline. Lo que nos corresponde: la lucha de los negros y mulatos por la igualdad en Cuba, 1886-1912. La Habana: Ediciones Imagen Contemporánea, 2000.

HOFFNUNG-GARSKOF, Jesse. The Migrations of Arturo Schomburg: On Being Antillano, Negro, and Puerto Rican in New York 1891-1938. Journal of American Ethnic History, Urbana, Illinois: University of Illinois Press, vol. 21, n. 1, p. 3-49, 2001. .

HOFFNUNG-GARSKOF, Jesse. Racial Migrations: New York City and the Revolutionary Politics of the Spanish Caribbean. Princeton: Princeton University Press, 2019.

EL HONORABLE... El Honorable Dr. Betances. Disponível em: https://upload.wikimedia.org/wikipedia/commons/e/e6/Ramon_Emeterio_Betances_sitting.jpg. Acesso em: 25 jun. 2020.

KNIGHT, Franklin W. Slave society in Cuba during the nineteenth century. Madison: University of Wisconsin Press, 1986 [1970].

MACEO, Antonio. Antonio Maceo: ideología política, cartas y otros documentos. Vol. I: 1870-1894. La Habana: Editorial de Ciencias Sociales, 1998.

MACEO, Antonio. Carta dirigida a distinguido señor, por Antonio Maceo; Donativos y Remisiones, maço 95, documento 49 (Arquivo Nacional de Cuba, ANC). s.d.

MACEO, Antonio. Carta dirigida ao General José Lamothe por Antonio Maceo; Donativos y Remisiones, maço 95, documento 21, Porto Príncipe (Arquivo Nacional de Cuba, ANC). 23 set. 1879.

MACEO, Antonio. Carta dirigida ao General Máximo Gómez por Antonio Maceo; Donativos y Remisiones, maço 95, documento 74, Ilhas Turcas (Arquivo Nacional de Cuba, ANC). 6 fev. 1880.

MACEO, Antonio. Carta dirigida ao General Máximo Gómez ao parecer por Antonio Maceo; Donativos y Remisiones, maço 95, documento 74, Kingston (Arquivo Nacional de Cuba, ANC). 18 y 23 jun. 1886.

MACEO, Antonio. Cinco escritos al parecer por Antonio Maceo; Donativos y Remisiones, maço 95, documento 95 (Arquivo Nacional de Cuba, ANC). s.d.

MACEO, Antonio. Escrito dirigido a señores por Antonio Maceo; Donativos y Remisiones, maço 95, documento 51 (Arquivo Nacional de Cuba, ANC). s.d.

MACÍAS, J. M. Carta dirigida a Antonio Maceo por J. M. Macías, Nova Iorque; Donativos y Remisiones, maço 97, documento 195 (Arquivo Nacional de Cuba, ANC). 22 abr. 1878. 
MATA, Iacy Maia. Conspirações da raça de cor: escravidão, liberdade e tensões raciais em Santiago de Cuba (1864-1881). Campinas: Editora Unicamp, 2015.

MARTÍ, José. Obras completas - Edición Crítica (1882-1884). Estados Unidos (volumen I). Tomo 17. La Habana: Centro de Estudios Martianos; Buenos Aires: CLACSO, 2016.

MORENO FRAGINALS, Manuel. Cuba/España, España/Cuba: Historia común. Barcelona: Critica, 2002.

LOS NEGROS... Los negros y mulatos cubanos residentes en Jamaica, ante la America Independiente, con motivo del Bando del General Blanco, prohibiendo la entrada de los hombres de color en la isla de Cuba, procedentes de pueblos estranjeros, Kinsgton; Diversos 7, fl. 511(Arquivo Geral das Índias, AGI). 26 out. 1879.

ORTIZ, Paul. One of History's Foremost Anti-Slavery Organizers Is Often Left Out of the Black History Month Story. Jan. 2018. Disponível em: https://time.com/5124917/ black-history-month-henry-highland-garnet/. Acesso em 23: jun. 1920.

PAQUETTE, Robert L. Sugar is made with blood: the conspiracy of La Escalera and the conflitct between empires over slavery in Cuba. Middletown, Conn.: Wesleyan University Press, 1988.

PEAKE, Jak. "Watching the Waters": Tropic flows in the Harlem Renaissance, Black Internationalism and other currents. Radical Americas, vol. 3, 2018. Disponível em: https://www.researchgate.net/figure/Portrait-of-Antonio-Maceo-from-Booker-T-Washington-Fannie-Barrier-Williams-and-Norman_fig8_327950141. Acesso em: 8 set. 2019.

PICHARDO VIÑALS, Hortensia. Documentos para la história de Cuba. T. 1. La Habana: Editorial de Ciencias Sociales, 1973.

PINTO, Antonio J. Negro sobre blanco: La conspiración esclava de 1812 en Puerto Rico. Caribbean Studies, San Juan, vol. 40, n. 1, p. 121-149, jan.-jun. 2012.

POLAVIEJA, Camilo. Telegrama do comandante geral Camilo Polavieja dirigido desde Cuba ao capitão geral em Conspiración de la Raza de Color, Santiago de Cuba; Diversos 8 (Arquivo Geral das Índias, AGI). 10 dez. 1880, p. 6.

RAMA, Carlos. M. La idea de la Federación Antillana en los independentistas puertorriqueños del siglo XIX. Río Piedras, P. R.: Ediciones Librería Internacional, 1971.

REYES-SANTOS, Irmary. On Pan-Antillean Politics: Ramón Emeterio Betances and Gregorio Luperón Speak to the Present. Callaloo, Baltimore: John Hopkins University, v. 36, n. 1, p. 142-157, 2013.

SCHMIDT-NOWARA, Christopher. Empire and Antislavery: Spain, Cuba, and Puerto Rico, 1833-1874. Pittsburgh: University of Pittsburgh Press, 1999.

SCOTT, Rebecca J. Emancipação escrava em Cuba: A transição para o trabalho livre, 1860-1899. Campinas: Editora da Unicamp; Rio de Janeiro: Paz e Terra, 1991.

SCOTT, Rebecca J. Grados de libertad: Cuba y Luisiana después de la esclavitud. La Habana: Editorial de Ciencias Sociales, 2006. 
SCOTTRON, S. R. Cartas dirigidas a Antonio Maceo por S. R. Scottron, New York. Arquivo Nacional de Cuba (ANC), Donativos y Remisiones, maço 97, documento 254, 17 abr. 1878.

SUÁREZ DÍAZ, Ada. El Doctor Emeterio Betances y la abolición de la esclavitud. Porto Rico: Editorial del Instituto de Cultura Puertorriqueña, 1980.

TORRES-CUEVAS, Eduardo. Historia de la masonería cubana. Seis ensayos. La Habana: Imagen Contemporánea, 2004.

TROY, Rev. William. Loyalty of the Colored Man to the United States Government, their valor in conflict, their Worth to the government in the time of need and the little notice given to deeds of heroism. The late conflict with Cuba, the Spanish government and the Philippines. Containing Brief Accounts of the Life of General Antonio Maceo and General Aguinaldo. Philadelphia: The Christian Banner Print, 1900.

WASHINGTON, Booker T.; WILLIAMS, Fannie Barrier; WOOD, Norman B. A New Negro for a New Century, 1900, p. 25.

ZACAÏR, Philippe. Haiti on His Mind: Antonio Maceo and Caribbeaness. Caribbean Studies, Rio Piedras: Institute of Caribbean Studies, vol. 33, n. 1, p. 47-78, jan-jun. 2005.

\section{NOTAS}

${ }^{1}$ Esta pesquisa foi financiada pela CAPES através do estágio pós-doutoral na Universidade de Nova Iorque e contou com o apoio do Programa ProPesqUFBA/MCTI. Agradeço aos pareceristas anônimos da Revista Brasileira de História e à linha de pesquisa Escravidão e Invenção da Liberdade/UFBA, em especial a João José Reis, pela devolução do texto com sugestões e comentários.

2 Àquela altura, sociedades abolicionistas atuavam havia décadas nos Estados Unidos e o abolicionismo espanhol se fortalecia com a formação da Sociedade Abolicionista Espanhola em 1865 (Schmidt-Nowara, 1999, p. 100-125).

${ }^{3}$ Cf. Expediente instruido..., 29 dez. 1865. As traduções são de minha autoria. Em função dos limites do texto, não foi possível colocar as transcrições originais nas notas de rodapé.

${ }^{4}$ Em 1867, uma conspiração em Cuba envolvendo negros livres e escravos para "matar os brancos" e acabar com a escravidão foi descoberta pelos espanhóis; em 1868, eclodiu uma longa insurreição anticolonial, conhecida como Guerra de Dez Anos; em 1879-80, houve a chamada Guerra Pequena (Mata, 2015). Porto Rico, por sua vez, foi palco do chamado Grito de Lares, rebelião armada fomentada pelo Comitê Revolucionário de Porto Rico, fundado por Betances. A insurreição, que pretendia não apenas a independência, mas transformações sociais, foi rapidamente derrotada pelos espanhóis (Arpini, 2008, p. 125-137).

${ }^{5}$ A American and Foreign Anti-Slavery Society foi uma importante sociedade abolicionista dos Estados Unidos. Após a Guerra Civil, o reverendo Henry Highland Garnet, seu 
presidente, convocou os abolicionistas a continuarem lutando contra a escravidão em Cuba e no Brasil. A sociedade atuava organizando meetings, comitês antiescravistas e demandando que os Estados Unidos dessem suporte aos patriotas cubanos que lutavam contra a Espanha na década de 1870 (Ortiz, 2018).

${ }^{6}$ Independentistas cubanos, alguns filiados à maçonaria, alimentados por ideais de liberdade e igualdade e defensores da emancipação gradual, recrutaram escravos e gestaram o ideal nacionalista de fraternidade racial (Ferrer, 1999, p. 37-42). O Exército Libertador, multirracial, tornou-se um símbolo dessa convivência e aliança inter-racial, embora estudos já apontem como eram reproduzidas, no corpo militar, hierarquias raciais e discriminações (Ferrer, 1999; Helg, 2000).

${ }^{7}$ Os termos "raça de cor", "classe de cor", "gente de cor", "homens de cor", "livres de cor", "população de cor", "mulato" e "pardo" são usados neste texto para respeitar o disposto na documentação e na bibliografia sobre o Caribe espanhol.

${ }^{8}$ Cf. Discurso em la logia masónica de Port-au-Prince (Betances, 2008, p. 116). Sobre a participação de Betances na maçonaria, ver Arroyo-Martínez (2011); sobre o papel da maçonaria no movimento independentista cubano, ver Eduardo Torres-Cuevas (2004).

${ }^{9}$ Maceo e Betances foram classificados por muitos dos seus contemporâneos e por parte da bibliografia como "mulatos" (Buscaglia-Salgado, 2016, p. 245-256). Apesar disso, o tema da mestiçagem não é discutido neste artigo porque não era objeto de preocupação destes ativistas, que se intitulavam "homens de cor", descendentes da raça africana, e mobilizavam a categoria "raça de cor" para reivindicar direitos políticos (Mata, 2015, p. 178-183). Sobre o pai de Alexandre Pétion, Betances diz: "o branco que morreu sem ter dado a seu filho mais que mostras de ódio e desprezo não merece que a posteridade repita seu nome" (Betances, 2013, p. 216).

${ }^{10}$ Betances viveu cinco anos no Haiti (1870-75) como médico e ativista (Arroyo-Martínez, 2011); Maceo esteve no Haiti em 1879 (Zacaïr, 2005, p. 53, 59).

${ }^{11}$ No bojo dos movimentos anticoloniais foram gestados projetos, com diferentes matizes, de unidade política das Antilhas através da formação de uma Confederação Caribenha ou Antilhana (Busclaglia-Salgado, 2003, p. 245-253; Mata, 2015, p. 232-241). Em 1867, Betances conclamou cubanos e porto-riquenhos a se unir contra a Espanha: "somos irmãos, somos um na desgraça, sejamos também um na Revolução, e na independência de Cuba e Porto Rico. Assim poderemos formar a Confederação das Antilhas" (Rama, 1971, p. 18).

${ }^{12}$ Aqui tomo emprestado o argumento de Reyes-Santos sobre o ativismo político de Betances e Gregorio Luperón (Reyes-Santos, 2013, p. 143).

${ }^{13}$ Zacaïr (2005, p. 51-52) chama a atenção para a singularidade de Maceo ao incluir o Haiti na "agenda caribenha", e para aquilo que denomina de sentimento dos afro-cubanos em relação ao Haiti, mas não discute que papel a raça joga nessa escolha, tampouco analisa a postura semelhante de Betances.

${ }^{14}$ Após a morte de Dessalines, o Haiti foi dividido em dois: o norte, transformado em Rei- 
no do Haiti, passou a ser governado por Henry Christophe, e o sul tornou-se a República do Haiti, sob o governo de Alexandre Pétion (Blackburn, 2002, p. 273).

${ }^{15} \mathrm{O}$ jornal La Revolucion, órgão da Junta Central Republicana de Cuba e Porto Rico, circulou de 1869 a 1875. Primeiro foi chamado de La Revolucion. Cuba y Puerto Rico; posteriormente, apenas La Revolucion, e, por fim, em 1874, La Revolucion de Cuba (Chaar-Pérez, 2013, p. 31, nota 15).

${ }^{16}$ Sobre a presença e atuação política de cubanos e porto-riquenhos na cidade de Nova Iorque, ver Jesse Hoffnung-Garskof (2019).

${ }^{17}$ Em 1879, a Sociedade Antropológica de Cuba dava a definição de cubano como "homem branco nascido em Cuba". Ver: Moreno Fraginals, 2002, p. 224. Abolicionistas afro-americanos como Frederick Douglas já haviam usado a experiência da Revolução haitiana para exaltar os negros como sujeitos históricos (Chaar-Pérez, 2013, p. 17-18).

${ }^{18}$ Para Zacaïr (2005, p. 53), Maceo tornara-se o símbolo da "luta afro-cubana por liberdade e igualdade".

${ }^{19}$ Maceo esteve em Nova Orleans em 1884, hospedando-se no Templo Maçônico Perseverança, frequentado pela população de cor de N. Orleans (Scott, 2006, p. 86-87, 202).

${ }^{20}$ Poema escrito por Stella A. E. Brazley sobre o regimento negro enviado a Cuba (Scott, 2006, p. 208-209).

Artigo recebido em 13 de abril de 2020. Aprovado em 29 de junho de 2020. 